\title{
Home Sickness, Social Connected and Academic Performance in Hostelites
}

\author{
Fatima Mehmood ${ }^{1}$, Ms Rabia Jameel ${ }^{2}$, Aiesha Malik ${ }^{3}$ \\ ${ }^{1}$ Riphah Institute of Clinical and Professional Psychology, Riphah International University, Lahore, Pakistan \\ ${ }^{2}$ Lecturer, Riphah Institute of Clinical and Professional Psychology, Riphah International University, Lahore \\ ${ }^{3}$ Riphah College of Rehabilitation Sciences, Riphah International University, Lahore, Pakistan
}

Corresponding author: Fatima Mehmood; psychologistfatima15@gmail.com

Received 09 October 2020;

Accepted 16 October 2020;

Published 04 November 2020;

\begin{abstract}
The present study aimed to inspect the relationship among home sickness, social connectedness, and academic performance. The correlational examination configuration was utilized in this investigation. The $\mathrm{N}=300$ (150 males and 150 females) test of understudies were taken from various private inns by utilizing purposive examining strategy. The period of test was 18-25 years, M (SD) 2.58 (1.910). The appraisal devices were utilized, Homesickness scale (Heajong, 1999), Social Connectedness Scale Revised (Richard M Lee, 2001) and Academic Performance scale (Zahoor Ahmad, 2018). Examination of correlational was run so as to explore the connection between home disorder, social connectedness and scholarly execution. Control through cycle investigation was utilized to locate the directing function of social connectedness on home infection and scholastic execution. Free example t-test was utilized to quantify the distinction of factors. Results uncovered that home disorder, social connectedness and scholastic execution has non-critical relationship with one another. It was likewise discovered that social connectedness doesn't directing on the relationship of home ailment and scholarly execution. The results of this exploration additionally appeared there was no sexual orientation contrasts in scholastic execution.
\end{abstract}

Key words: Home Sickness, Hostelites, Social Connectedness, Students and Academic Performance.

\section{Introduction}

The purpose of the assessment will to take a gander at the connection between achiness to visit the family, social connectedness and insightful execution in hostelites understudies (Ward, Stoker and Ward, 1996).

\section{Academic Performance}

Planning is one of the crucial viewpoints that not just shows the key aptitudes, cutoff points, and information among the people, yet near prompts, considering, progress and progress of the people, structure, and country with everything considered. An informed individual isn't just coordinated to achieve his ideal targets and objections, yet on the other hand, can deliver a significant commitment towards the thriving of the structure. The planning of instructive information, aptitudes, cutoff points, and cutoff points among the people is strengthened through learning and scholarly execution. In optional schools, various pieces that contribute a colossal part in improving the rapid introduction of understudies. The gifted presentation picks the future goals and focal motivations behind understudies. What subject they will put basic vitality in schools and colleges, which instructive establishments they will get enlisted into, what calling openings they would take up, etc. (Kapur, 2018). ). Precisely when educators complete the systems for remunerating staggering execution, by then they would be persuaded to take a gander at and improve their useful execution. Optional school understudies ordinarily having a spot with high society and wealthy families know and might want to have a not all that awful work (Kapur, 2018). The tight character ascribes or features set out to underlie the expansive Big Five character factors are generally more grounded pointers of educational execution than are essentially the Big Five character factors (Connor, 2007).

\section{Homesickness}

Yearning to get back is the difficulty or incapacitating achieved by a genuine or anticipated bundle from home (Thurber, 1995). Its mental brand name is attracting thoughts of home and association objects. Victims dependably report a mix of tricky and tense reactions, pulled back direct, and weight focusing on guides insignificant toward home (Thurber and Sigman, 1998). In its smooth structure, longing to get back prompts the improvement of adjusting aptitudes and moves sound association rehearses, for instance, fortifying contact with loved ones (Hendrickson, Rosen and Aune, 2010).

\section{Social Connectedness}


Social ties follows a regulated system getting some information about a partner, approach for capable help, or talk with constantly (PNAS, 2009). The necessity for social affiliation is a fundamental human basis, and it is logically sure that feeling socially related present's psychological and physical clinical favorable circumstances (Hutcherson, C. A., Seppala, 2008).

Social connectedness was hypothesized to mediate the effects of social assistance in comfortable associations and general social ability on extents of horror and certainty (Keith and Renee, 2006).

\section{Literature Review}

A assessment was directed to take a gander at the factors that anticipate self-rule are dissected among 209 school understudies in their fundamental year in the University of Dammam, Saudi Arabia. Combination of data was driven in the school year's resulting semester. Considering the results, immense positive relations exist between social connectedness, self-suitability and balance, with self-rule. Likewise, the results revealed that social connectedness and balance are markers of understudies' self-rule, anyway not self-reasonability. Added to this, the result revealed a basic difference in the association among balance and self-rule among female understudies, with various elements irrelevant for the two sexual directions. Along these lines, it will in general be communicated that cutting-edge training authorities and academicians may focus on the assessment and the improvement of the understudies' aptitudes to the extent self-rule (Jdaitawi, 2015).

Another examination was directed to find explanations behind achiness to visit the family and how a longing to return home impact on insightful execution of understudy's introduction. At this moment scales are utilized; home cleared out a parcel and home cleared out the agony. In like manner, section factors add to check the understudy's degree of home difficulty, sex, residency and parent's guidance. Results show that away from in GPA of the primary semester and first-year upkeep on account of achiness to visit the family (Sun, Hagedorn and Zhang, 2016).

Moreover, an investigation was coordinated to see longing to return home wonders and its relationship with cellphone commitment, adaptability, social blend, and insightful joining. Using a cross-sectional survey strategy with defined analyzing at a school in Thailand found that a fundamental condition model had the alternative to explain 36 percent of the difference in longing to return home (n 1/4 220). Through improving academic and social compromise, quality, and reducing cellphone affiliation, steps can be produced to diminish the results of achiness to visit the family upon understudies (Thomas, 2017).

\section{Hypothesis}

- There is likely to be a negative relationship among homesickness and academic performance in hostelites students.

- $\quad$ There is likely to be a positive relationship among social connectedness and academic performance in hostelites students.

- Males are likely to exhibit high academic performance than females in hostelites.

- Social connectedness is likely to moderate on the relationship of home sickness and academic performance.

\section{Method}

\section{Research Design}

The flow inquires about was used to explore the relationship among achiness to go home, social connectedness and scholarly execution in hostelites understudies. In this way, the investigation structure of momentum explore was a correlational research plan (Kothari, 2004).

\section{Sampling Size and Sampling Strategy}

Purposive testing strategies were utilized to gather information. The example size was 300 (150 guys, 150 females). Test size was controlled by the G-power examination.

\section{Inclusion criteria}

- Age go (18 to 25$)$ was remembered for the present investigation.

- Hostel understudies were remembered for the present examination.

- Both males and females were remembered for the present investigation.

- Only private hostels were remembered for the present examination.

- Exclusion criteria

- Participants who have any physiological incapacity or mental sickness was prohibited from the present research.

- Students with a drug abuser were barred from the present research.

\section{Results}

The point of the examination was to investigate the relationship among Home Sickness, Social Connectedness and Academic Performance in Hostelites understudies.

The information was dissected utilizing Statistical Packages for Social Science, rendition 21(SPSS-21). The Cronbach's Alpha of the scales was getting utilizing unwavering quality investigation. To clarify the inner consistency of estimating instruments utilized in inquiring about. The information was examined by utilizing Descriptive Statistics and Inferential Statistics.

Distinct Statistics used to reports the mean, standard deviation, recurrence, level of segment factors and Inferential Statistics additionally used in which PPMCC was hurried to watch the correlation among Home Sickness, Social Connectedness, and Academic Performance.

Control investigation was utilized to evaluate the directing job of Social Connectedness with Home Sickness and Academic Performance.

\section{Reliability Analysis}

Elucidating Statistics were utilized to get to Frequencies, Percentage, Mean and Standard Deviation of Demographics and the investigation factors. Alpha qualities were determined to discover inward textures of study factors.

Table 1: Segment Characteristics of Participants ( $=300)$ 


\begin{tabular}{|l|l|}
\hline Demographic Variables & $\mathrm{f}(\%) \mathrm{M}(\mathrm{SD})$ \\
\hline Age & $2.58(1.910)$ \\
\hline Education & \\
\hline Under Graduate & $283(94.3)$ \\
\hline Post Graduate & $17(5.7)$ \\
\hline Duration in Hostel & \\
\hline 12 months & $55(18.3)$ \\
\hline 24 months & $95(31.7)$ \\
\hline 48 months & $66(22)$ \\
\hline Satisfied & $45(15)$ \\
\hline Not Satisfied & \\
\hline Satisfied & $96(32)$ \\
\hline Not Satisfied & $204(68)$ \\
\hline Roommate Satisfaction & \\
\hline Satisfied & $239(79.7)$ \\
\hline Hostel Environment & $61(20.3)$ \\
\hline Not Satisfied & \\
\hline Room Satisfaction & $243(81)$ \\
\hline Satisfied & $57(19)$ \\
\hline Not Satisfied & \\
\hline
\end{tabular}

Note: $f=$ frequency, $\%=$ percentage, $M(S D)=$ Standard Deviation

Table no1 of the segment of members shows that more college understudies participate in this study than graduate's students that were accommodated in hostels from maximum 2 years.
Frequency of students shows that mostly undergraduate's students were living in hostels than graduates. Students who were living in hostel were satisfied from their rooms and roommates but they were not satisfied with hostel mess.

Table 2: Psychometric Properties of Questionnaires

\begin{tabular}{|l|c|c|c|c|c|c|c|c|}
\hline Scale & K & \multicolumn{2}{|c|}{ M } & \multicolumn{2}{|c|}{ SD } & Potential & Actual & $\alpha$ \\
\hline & & Min & Max & Min & Max & & & \\
\hline & & & & & & & & \\
\hline Home Sick & 20 & 60.11 & 13.18 & 20 & 100 & 20 & 99 & .84 \\
\hline Social Con & 20 & 71.08 & 12.42 & 20 & 120 & 20 & 103 & .77 \\
\hline Aca Per & 51 & 119.25 & 18.54 & 51 & 255 & 72 & 176 & .88 \\
\hline
\end{tabular}

Note: $K=$ Number of things in the scale, $M=$ Mean, $S D=$ Standard Deviation, Min=Minimum Score,Max=Maximum Score, $\alpha=$ Reliability Coproductive

The psychometric properties consequences of the present research were shown in table no 2 Results explained the Cronbach alpha of Academic Performance Scale has high reliability .88. Social Connectedness Scale has moderate reliability .77. However Home Sickness has also high reliability.

\section{Correlation Analysis}

Pearson Product Moment correlation was used to investigate the correlation among study variables. Table 4.4 shows relationship among Home Sickness, Social Connectedness and Academic Performance.

Table 3 Pearson Product Moment Correlation of Home Sickness, Social Connectedness, and Academic Performance

\begin{tabular}{|l|l|l|l|l|l|l|l|l|l|l|l|l|l|l|}
\hline Measures & 1 & 2 & 3 & 4 & 5 & 6 & 7 & 8 & 9 & 10 & 11 & M & SD \\
\hline Home Sickness - & & .014 & .003 & -.034 & -.015 & 0.55 & .031 & -.015 & -.032 & .047 & -.017 & 60.11 & 13.18 \\
\hline $\begin{array}{l}\text { Social } \\
\text { Connectedness - }\end{array}$ & - & - & .006 & -.084 & -.043 & $.166^{* *}$ & -.02 & $.116^{*}$ & .028 & -.109 & -.003 & 71.08 & 12.41 \\
\hline $\begin{array}{l}\text { Academic } \\
\text { Performance - }\end{array}$ & - & - & - & -.001 & $.304^{* *}$ & $.465^{* *}$ & $.722^{* *}$ & $.722^{* *}$ & $.795^{* *}$ & $.795^{*}$ & .871 & 121.62 & 18.86 \\
\hline
\end{tabular}

Note: $M=$ Mean, $S D=$ Standard Deviation, ** correlation is significant at the 0.01 level $(2$ tailed), * correlation is significant at the 0.05 level (2-tailed)

Pearson Product Moment Correlation was conducted to examine the relationship between variables. Results reveals that Home

Sickness has non-significant relationship with Social

Connectedness. Home Sickness has non-significant relationship

Table 4: Moderation Analysis of Home Sickness, Social Connectedness and Academic Performance.

\begin{tabular}{|l|l|l|l|l|l|l|l|l|l|}
\hline Variables & $\mathrm{R}$ & $\mathrm{F}$ & $\mathrm{R}^{2}$ & $\mathrm{~B}$ & $\mathrm{SE}$ & $\mathrm{T}$ & $\mathrm{P}$ & LLCI & ULCI \\
\hline HS & & & & -.148 & .325 & -.456 & .648 & -.790 & .492 \\
\hline SC & & & & -.139 & .279 & -.498 & .618 & -.690 & .411 \\
\hline Interaction-1 & .029 & .841 & .000 & .0023 & -.0048 & -.4856 & .6276 & -.0070 & .0117 \\
\hline
\end{tabular}

Note: $B=$ Stander Coefficient, SE=Standard Error, $p=$ Significant Value, $L L=$ Lower Level, $U L=U p p e r$ Level, $R 2=$ Adjusted $R$-square with Academic Performance. Also Social Connectedness has nonsignificant relationship with Academic Performance. 
Process by Hayes (2013) was used to test the hypothesis of moderation. Table 4. showed moderating effect of Social Connectedness on the relationship of Home Sickness (IV) and Academic Performance (DV). The results shows not significant interaction effect of Social Connectedness on Home Sickness and Academic performance.

\section{Independent sample t-test Analysis}

Independent sample t-test examination was utilized to research the contrast between methods for gender differences.

Table 5: Independent Sample t-test Comparing Academic Performance in Men and Women ( $\mathbf{N = 3 0 0 )}$

\begin{tabular}{|c|c|c|c|c|c|c|c|}
\hline \multirow[t]{2}{*}{ Variables } & & $\begin{array}{l}\text { Males } \\
(\mathrm{N}=150)\end{array}$ & \multicolumn{2}{|c|}{$\begin{array}{l}\text { Females } \\
(\mathrm{N}=150)\end{array}$} & \multicolumn{2}{|c|}{$95 \% \mathrm{CI}$} & \multirow[b]{2}{*}{ Cohen'sd } \\
\hline & & $\mathrm{SD}$ & SD & $\mathrm{T}$ & LL & UL & \\
\hline $\mathrm{M}$ & & & & & $\mathrm{P}$ & & \\
\hline $\begin{array}{l}\text { Academic } \\
\text { Performance }\end{array}$ & 120.68 & 20.33122 .55 & $17.29-.85$ & $.391-6.17$ & 2.420 .09 & & \\
\hline
\end{tabular}

Note: $C I=$ Confidence Interval, $L L=$ Lower Limit, $U L=$ Upper Limit

Independent sample t-test examination demonstrated that there were minor changes in scholarly execution among guys and females.

\section{Discussion}

The result of the current study showed that home sickness has a significant negative connection among academic performance in hostelites. Burt (1993) drove investigate on academic execution and home difficulty. Results show that the home cleared out understudies don't zero in suitably on their educational tasks and they don't perform well. Moreover, results of current study have shown that significant negative relationship between social connectedness and academic performance. Malek (2015) investigate was composed to assess the positive association between social connectedness and academic execution. The examination reveals that understudies who were outstandingly socially related had less test disquiet. Furthermore, findings of the current investigation revealed that males academic performance are better than females in hostelites. A study was conducted to assess males and females academic performance. Verboom (2014) coordinated examination on males and females academic execution and effect of weight on looks at. Exploration reveals that females had dynamically troublesome issues and high educational execution as a difference with males.

\section{Conclusion}

Hence, it's concluded that perceive the components that sway the social coordinated effort and academic execution of home cleared out understudies in hostelites. After the comprehension and examination of the data, revelations of the current assessment wrapped up the results. That there is a non-imperative relationship of home issue with academic execution. The delayed consequence of the assessment was demonstrated a non-basic association between home some infirmity and social connectedness. Furthermore, consequences of the current assessment showed up there is no coordinating effect of social connectedness on home contamination and academic execution.

The Conclusions section should clearly explain the main findings and implications of the work, highlighting its importance and relevance.

\section{Data Availability}

Information was gathered from various hostels (government and private). Authorizations were taken from the concerned people to gather the information. Permission letters was issued by the university. They was informed about the aim of the research. All research questionnaires was administered by the researcher. The researcher was available in any case of trouble about every item. The information sheet was provided to the participants previous to the study and they was also be ask to sign the consent form to assure that they was participating voluntarily. They was also be informed that they be able to remove from the research anytime and their participation would be appreciated. They was also be sure that data taken from them was only use for investigation and academic purpose and if feel any kind of stress during the administration of the questionnaires they was help from the psychologist.

\section{Conflicts of Interest}

"The author declare that there is no conflict of interest regarding the publication of this paper."

\section{References}

[1] Jarvis P Towards a comprehensive theory of human learning [Book]. - New York : Routledge, 2006. Johnson Y. George D. The Impact of Whatsapp Messenger Usage on Students Performance in Tertiary Institutions in Ghana [Journal]. - 2014. - 6 : Vol. 5.

[2] Maehr, M. L., \& Meyer, H. A. (1997). Understanding motivation and schooling: Where we've been, where we are, and where we need to go. Educational Psychology Review, 9, 371-408.

[3] Mansfield, C. (2010). Motivating adolescents: Goals for Australian students in secondary schools. Australian

[4] Journal of Educational \& Developmental Psychology, 10, 44-55. Retrieved from Jamali, M., Abolhassani H.: Different aspect of social network analysis, Web Intelligence, 2006. WI 2006. IEEE/WIC/ACM International Conference, pp 66-72

[5] Cho, H., Gay, G., Davidson, B., Ingraffea, A.: Social networks, communication styles, and learning performance in a CSCL community, Computers \& Education 49, 2007., pp 309-329

[6] Rudasill, K., Reio, T., Stipanovic, N., \& Taylor, J. (2010). A longitudinal study of student-teacher relationship quality, difficult temperament, and risky behavior from childhood to early adolescence. Journal of School Psychology, 48, 389-412. 
[7] Rueger, S., Malecki, C., \& Demaray, M. (2010). Relationship between multiple sources of perceived social support and psychological and academic adjustment in early adolescence: Comparisons across gender. Journal of Youth and Adolescence, 39, 47-61.

[8] Henderson, D. X., \& Green, J. (2014). Using mixed methods to explore resilience, social connectedness, and resuspension among youth in a community-based alternative to suspension program. International Journal of Child, Youth, and Family Studies, 5(3), 423-446.

[9] Henderson, D. X., \& McClinton, J. (2016). A qualitative exploration of suspended youths' social connectedness in a community-based intervention program. Child \& Youth Services. Advance online publication. doi: 10.1080/0145935X.2015.1083402

[10] Serwaa, N.A.; Dadzie, P.S. Social media use and its implications on child behaviour: A study of a basic school in Ghana. Int. J. Soc. Media Interact. Learn. Environ. 2015, 3, 49-62.

[11] Sendurur, P.; Sendurur, E.; Yilmaz, R. Examination of the social network sites usage patterns of pre-service teachers. Comput. Hum. Behav. 2015, 51, 188-194.

[12] Van Tilburg, M.A., Vingerhoets, A.J., \& Van Heck, G.L. (1996). Homesickness: A review of the literature.

[13] Psychological medicine, 26(05), 899-912.

[14] Stroebe, M., Schut, H., Nauta, M.H. (2016). Is homesickness a mini-grief? Development of a dual process model. Clinical Psychological Science, 4 (2), 344-358.

[15] Yakunnina, E., Weigold, I., Weigold, A., Hercegovac, S., \& Elsayed, N. (2013). International students' personal and multicultural strengths: Reducing acculturative stress and promoting adjustment. Journal of Counseling and Development, 91(2), 216e223. https://doi.org/10.1002/ j.1556-6676.2013.00088.x.

[16] Yildirim, C., \& Correia, A. (2015). Exploring the dimensions of nomophobia: Development and validation of a self-reported questionnaire. Computers in Human Behavior, 49, 130e137.

[17] Rienties, B., Grohnert, T., Kommers, P., Niemantsverdriet, S., \& Nijhuis, J. (2011). Academic and social integration of international and local students at five business schools, a cross-institutional comparison. In P. Van den Bossche, W. H. Gijselaers \& R. G. Milter (Eds.), Building learning experiences in a changing world (Vol. 3, pp. 121-137). Netherlands: Springer.

[18] Zhou, Y., Jindal-Snape, D., Topping, K., \& Todman, J. (2008). Theoretical models of culture shock and adaptation in international students in higher education. Studies in Higher Education, 33(1), 63-75.

[19] Ogunsola, O.K., Osuolale, K.A., \& Ojo, A.O. (2014). Parental and Related Factors Affecting

[20] Students' Academic Achievement in Oyo State, Nigeria. World Academy of Science,

[21] Engineering and Technology International Journal of Educational and Pedagogical

[22] Sciences, 8(9), 3137-3144. Retrieved April 25, 2018 from Feldman, K.A., Smart, J.C., \& Ethington, C.A. (2004). What do college students have to lose?

[23] Exploring the outcomes of differences in personenvironment fits. Journal of Higher Education,

[24] 75(5), 528-555.

[25] Blane, D, Brunner, E \& Wilkinson, R, 1996, Health and social organisation: Towards a health policy for the $21 \mathrm{st}$ century, Routledge, London, p. 12.

[26] Stansfeld, S, 2006, 'Social support and social cohesion', in R Wilkinson \& M Marmot (eds), Social determinants of health (2nd edn), Oxford University Press, Oxford, pp. $148-171$.

[27] Effective Change, 2007, Partnership resource for community arts, Victorian Health Promotion Foundation, Melbourne. 